\title{
The ErbB signalling pathway: protein expression and prognostic value in epithelial ovarian cancer
}

\section{P de Graeff', APG Crijns', KA ten Hoor', HG Klip', H Hollema², K Oien ${ }^{3}$, JM Bartlett ${ }^{4}$, GBA Wisman', GH de Bock ${ }^{5}$, EGE de Vries ${ }^{6}, S_{\text {de Jong }}{ }^{6}$ and AGJ van der Zee ${ }^{*, 1}$}

'Department of Gynaecologic Oncology, University Medical Centre Groningen, University of Groningen, Hanzeplein I, Groningen 97। 3 GZ, The Netherlands; ${ }^{2}$ Department of Pathology, University Medical Centre Groningen, University of Groningen, Hanzeplein I, Groningen 97 I 3 GZ, The Netherlands; ${ }^{3}$ Centre for Oncology and Applied Pharmacology, Cancer Research UK Beatson Laboratories, Garscube Estate, Switchback Road, Bearsden, Glasgow G6I IBD, UK; ${ }^{4}$ Endocrine Cancer Group, Western General Hospital, Edinburgh Cancer Research Centre, University of Edinburgh, Crewe Road South, Edinburgh EH4 2XR, UK; ${ }^{5}$ Department of Epidemiology and Statistics, University Medical Centre Groningen, University of Groningen, Hanzeplein I, Groningen 9713 GZ, The Netherlands; ${ }^{6}$ Department of Medical Oncology, University Medical Centre Groningen, University of Groningen, Hanzeplein I, Groningen 9713 GZ, The Netherlands

Ovarian cancer is the most frequent cause of death from gynaecological cancer in the Western world. Current prognostic factors do not allow reliable prediction of response to chemotherapy and survival for individual ovarian cancer patients. Epidermal growth factor receptor (EGFR) and HER-2/neu are frequently expressed in ovarian cancer but their prognostic value remains unclear. In this study, we investigated the expression and prognostic value of EGFR, EGFR variant III (EGFRvIII), HER-2/neu and important downstream signalling components in a large series of epithelial ovarian cancer patients. Immunohistochemical staining of EGFR, pEGFR, EGFRvIll, Her-2/neu, PTEN (phosphatase and tensin homologue deleted on chromosome 10), total and phosphorylated AKT ( $\mathrm{pAKT}$ ) and phosphorylated ERK ( $P E R K$ ) was performed in 232 primary tumours using the tissue microarray platform and related to clinicopathological characteristics and survival. In addition, EGFRvIll expression was determined in 45 tumours by RT-PCR. Our results show that negative PTEN immunostaining was associated with stage $1 /$ II disease $(P=0.006)$, non-serous tumour type $(P=0.042)$ and in multivariate analysis with a longer progression-free survival $(P=0.015)$. Negative PTEN staining also predicted improved progression-free survival in patients with grade III or undifferentiated serous carcinomas $(P=0.0 \mathrm{I} I)$. Positive pAKT staining was associated with advanced-stage disease $(P=0.006)$. Other proteins were expressed only at low levels, and were not associated with any clinicopathological parameter or survival. None of the tumours were positive for EGFRvIll. In conclusion, our results indicate that tumours showing negative PTEN staining could represent a subgroup of ovarian carcinomas with a relatively favourable prognosis.

British Journal of Cancer (2008) 99, 34I -349. doi:I0.1038/sj.bjc.660447I www.bjcancer.com

(c) 2008 Cancer Research UK

Keywords: ovarian cancer; prognosis; EGFR; HER-2/neu; PTEN; EGFRvIlI

Five-year survival of advanced-stage ovarian cancer patients remains only $15-25 \%$, despite intensive surgical treatment and combination chemotherapy. Development of intrinsic or acquired resistance to platinum-containing chemotherapy is the major obstacle in the treatment of patients with ovarian cancer (Bhoola and Hoskins, 2006). Current clinicopathological prognostic factors do not allow individualised prediction of response to chemotherapy or disease outcome. Identification of molecular biological prognostic factors would be of great value for more accurately classification of ovarian carcinomas into subtypes with a different clinical outcome, thereby possibly also enabling individualised treatment strategies (Crijns et al, 2006a).

Epidermal growth factor receptor (EGFR) and HER-2/neu are members of the erbB family of tyrosine kinase receptors. Aberrant

*Correspondence: Dr AGJ van der Zee;

E-mail: a.g.j.van.der.zee@og.umcg.nl

Revised 7 April 2008; accepted 22 May 2008 activity of EGFR and HER-2/neu has been shown to be important in tumour growth and development. Binding of ligand to the ectodomain of ErbB receptors results in receptor autophosphorylation and initiation of downstream signalling cascades, such as the PI3K/AKT pathway and the Ras/Raf/MEK/Erk pathway. Activation of these pathways in cancer has been associated with increased angiogenesis, metastasis, dedifferentiation, growth and protection from apoptosis (Yarden and Sliwkowski, 2001). Phosphatase and tensin homologue deleted on chromosome 10 (PTEN) directly antagonises the PI3K/AKT pathway by preventing the phosphorylation of AKT (Sansal and Sellers, 2004).

Several studies have shown that overexpression of HER-2/neu and EGFR, as well as alterations in their downstream targets AKT and extracellular signal-regulated kinase (ERK) is associated with resistance to platinum- and taxane-based chemotherapy. Treatment with agents directed against these proteins may enhance chemotherapy-induced cell death (Ciardiello et al, 2000; Altomare et al, 2004; Qiu et al, 2005; Lee et al, 2005b) The prognostic significance of EGFR and HER-2/neu has been extensively studied 
in ovarian cancer, but remains unclear. A recent meta-analysis revealed that abnormal expression of these markers appears to be associated with poor 5-year survival, but this is not a uniform finding (Crijns et al, 2003).

The EGFR variant III (EGFRvIII) lacks exons 2-7 of the extracellular domain of the receptor. Although EGFRvIII is unable to bind ligand, it is constitutively phosphorylated and able to activate downstream signalling pathways (Pedersen et al, 2001). EGFRvIII expression is thought to confer resistance to cisplatin and paclitaxel (Nagane et al, 1998; Montgomery et al, 2000). The two studies investigating EGFRvIII expression in ovarian cancer show conflicting results (Moscatello et al, 1995; Lassus et al, 2006).

The aim of the present study was to investigate the prognostic significance of EGFR and HER-2/neu, and their downstream targets AKT, ERK and PTEN in a large series of 232 epithelial ovarian cancer patients using the tissue microarray (TMA) platform. In addition to immunostaining, we determined the expression of EGFRvIII in more detail in a subset of 45 ovarian tumours using the more sensitive method RT-PCR.

\section{MATERIALS AND METHODS}

\section{Patients}

Since 1985 all clinicopathological and follow-up data of 329 epithelial ovarian cancer patients treated at the University Medical Centre Groningen have been prospectively stored in a database. All patients gave informed consent for data storage and tumour collection, and studies were conducted in accordance with the Declaration of Helsinki principles and institutional review board policies. For the current study all consecutive chemonaive ovarian cancer patients for whom sufficient paraffin-embedded tumour tissue and complete follow-up data were available were selected $(n=232)$.

Patients were surgically staged according to FIGO (International Federation of Gynaecology and Obstetrics) criteria (Cancer Committee of the International Federation of Gynaecology and Obstetrics, 1986). Optimal and suboptimal debulking was defined as the largest residual tumour lesions having a diameter of $<2 \mathrm{~cm}$ or $\geqslant 2 \mathrm{~cm}$. The histology of all carcinomas was determined by a gynaecological pathologist according to WHO (World Health Organization) criteria (Scully, 2004).

Response to chemotherapy was evaluated according to WHO criteria (World Health Organization, 1979). When indicated, intervention surgery was performed after three cycles of chemotherapy, while until 1996 second-look surgery was regularly performed after six cycles of chemotherapy.

\section{TMA construction and immunostaining}

Tissue microarrays were constructed as described previously (de Graeff et al, 2006). In total, four tissue cores from 232 primary tumours and 45 paired tumours obtained at second-look surgery or surgery for recurrent disease were included on eight TMAs.

Antigen retrieval methods, primary antibodies and detection techniques are provided as supplementary data. Sections $(4 \mu \mathrm{m})$ were de-paraffinised in xylene and endogenous peroxidase was blocked by incubation in $0.3 \%$ hydrogen peroxide for $30 \mathrm{~min}$. After antigen retrieval, slides were incubated in normal goat serum (HER-2/neu), horse serum (EGFR, pEGFR), bovine serum (phosphorylated AKT (pAKT), phosphorylated ERK (pERK), PTEN, total AKT) or blocking solution (Dako, Cambridgeshire, UK) for EGFR. For pEGFR, pAKT, pERK and PTEN staining, endogenous avidin and biotin activity was blocked using a blocking kit (Vector Laboratories, Burlingame, UK). HER-2/neu staining was performed in a Dako autostainer (Dako). Staining was visualised by 3'3-diaminobenzidine tetrahydrochloride and sections were counterstained with haematoxylin. EGFRvIII staining was kindly performed by Dr A Jungbluth, Ludwig Institute for Cancer Research, New York, USA.

Positive controls included separate TMA slides containing multiple tumour and normal tissues for EGFR and pEGFR, sections from tumours with known marker expression for HER2/neu and PTEN, ovarian cancer cell line A2780 for AKT, pAKT and ERK, and glioblastoma cell line U87 transfected with an EGFRvIII plasmid for EGFRvIII staining (Jungbluth et al, 2003). Negative controls were obtained by omission of the primary antibody, and by incubation with normal rabbit IgG for total AKT. All control experiments gave satisfactory results. Antigen preservation was verified by vimentin staining, which was positive in all tumour and control samples.

Evaluation of immunostaining was independently performed by two observers (KAH and PDG), blinded to clinical data. The agreement between the two observers was $>90 \%$. Discordant cases were reviewed with a gynaecological pathologist and were re-assigned on consensus of opinion.

HER-2/neu staining was scored according to the HercepTest protocol (Lebeau et al, 2001), and was considered positive when $>10 \%$ of tumour cells showed moderate or strong membrane staining. For EGFR and EGFRvIII, tumours demonstrating $>10 \%$ membrane staining were considered to show overexpression (Elie et al, 2004; Skirnisdottir et al, 2004; Cunningham et al, 2005). Overexpression of p-EGFR was defined as $>5 \%$ membrane or granular cytoplasmic staining (Han et al, 2004). Tumours were considered positive for AKT or ERK if $>10 \%$ of tumour cells showed positive cytoplasmic and/or nuclear staining (Kurose et al, 2001). Phosphatase and tensin homologue deleted on chromosome 10 staining in tumour sample was scored relative to staining in vascular endothelium (Gimm et al, 2000; Choe et al, 2003), and was regarded as negative when staining was completely absent in tumour tissue but present in vascular endothelium.

\section{RT - PCR for EGFRvIII}

We performed RT - PCR analysis on a subset of 45 frozen tumour samples, of which 35 showed positive immunostaining for (p)EGFR or downstream targets and 10 were completely negative. Positive controls included a glioblastoma tumour sample expressing both the wild-type EGFR (wtEGFR) and EGFRvIII, and a cell line transfected with an EGFRvIII plasmid (Jurkat.EGFRvIII; Bremer et al, 2005).

Extraction of RNA and cDNA synthesis was performed as previously described (Crijns et al, 2006b). We performed RT - PCR separately for EGFRvIII and the housekeeping gene GAPDH. Primers were $5^{\prime}$-GGGCTCTGGAGGAAAAGAAA- $3^{\prime}$ and $5^{\prime}$-AGGCC CTTCGCACTTCTTAC- $3^{\prime}$ for amplifying EGFRvIII and wtEGFR (Ji et al, 2006), and $5^{\prime}$-CACCCACTCCTCCACCTTTG- $3^{\prime}$ and $5^{\prime}$-CCAC CACCCTGTTGCTGTAG- $3^{\prime}$ for amplifying GAPDH. The protocol was as follows: initial denaturation at $95^{\circ} \mathrm{C}$ for $10 \mathrm{~min}$, followed by 30 (EGFRvIII) or 25 cycles $(G A P D H)$ of amplification ( $1 \mathrm{~min}$ at $95^{\circ} \mathrm{C}, 1 \mathrm{~min}$ at $56^{\circ} \mathrm{C}$ for EGFRviII and at $60^{\circ} \mathrm{C}$ for $\mathrm{GAPDH}$, and $90 \mathrm{~s}$ at $72^{\circ} \mathrm{C}$ ) and a final extension step at $72^{\circ} \mathrm{C}$ for $7 \mathrm{~min}$. The RT - PCR products (128 bp for EGFRvIII, $929 \mathrm{bp}$ for wtEGFR and $110 \mathrm{bp}$ for $G A P D H)$ were visualised by $1.5 \%$ agarose gel electrophoresis in $1 \times$ Tris-Borate EDTA buffer.

\section{Statistical analysis}

Statistical analysis was carried out using the SPSS 12.01 software package. Cut-off points for positive marker expression were determined a priori. All cases with $<2$ evaluable cores were excluded from analysis.

Comparisons between paired tumour samples obtained before and after chemotherapy were made using the Wilcoxon rank sum 
test. Associations between markers, and between markers and clinicopathological characteristics were performed using the $\chi^{2}$ or Fisher's exact test, where appropriate.

The end points investigated were progression-free and diseasespecific overall survival (PFS and OS), defined as the time from primary surgery until progression/relapse of the disease or death of ovarian cancer, respectively. Response to platinum-based chemotherapy could only be evaluated in patients who had measurable disease after primary surgery and/or during first-line chemotherapy $(n=130)$, and was defined according to WHO criteria (World Health Organization, 1979).

For univariate and multivariate survival analysis Cox proportional hazards model was used. Categorised covariates that were significant in univariate analysis were entered simultaneously into the multivariate model. Response to chemotherapy was analysed using logistic regression analysis. For this analysis, response was entered as a categorical variable (complete and partial response $v s$ stable and progressive disease). $P$-values $<0.05$ were considered statistically significant.

\section{RESULTS}

\section{Patients}

A total of 232 patients (median age 57.8 years, range 22-90) treated at the Groningen University Medical Centre between 1985 and 2002 were selected for the present study (Table 1). Of them 64 $(27.6 \%)$ patients presented with stage I/II disease and $166(71.5 \%)$

Table I Clinicopathological characteristics

\begin{tabular}{|c|c|c|}
\hline & \multicolumn{2}{|c|}{ All patients $(n=232)$} \\
\hline & $\mathbf{N}$ & $\%$ \\
\hline \multicolumn{3}{|l|}{ FIGO stage } \\
\hline Stage I & 45 & 19.4 \\
\hline Stage ॥ & 19 & 8.2 \\
\hline Stage III & 133 & 57.3 \\
\hline Stage IV & 33 & 14.2 \\
\hline Missing & 2 & 0.9 \\
\hline \multicolumn{3}{|l|}{ Tumour type } \\
\hline Serous & 129 & 55.6 \\
\hline Mucinous & 27 & 11.6 \\
\hline Clear cell & 17 & 7.3 \\
\hline Endometrioid & 33 & 14.2 \\
\hline Adenocarcinoma NOS & 9 & 3.9 \\
\hline Other & 17 & 7.3 \\
\hline \multicolumn{3}{|l|}{ Tumour grade } \\
\hline Grade I & 39 & 16.8 \\
\hline Grade ॥ & 51 & 22.0 \\
\hline Grade III & 104 & 44.8 \\
\hline Undifferentiated & 14 & 6.0 \\
\hline Missing & 24 & 10.3 \\
\hline \multicolumn{3}{|l|}{ Residual disease } \\
\hline$<2 \mathrm{~cm}$ & || $\mid$ & 47.8 \\
\hline$\geqslant 2 \mathrm{~cm}$ & 109 & 47.0 \\
\hline Missing & 12 & 5.2 \\
\hline \multicolumn{3}{|l|}{ Type of chemotherapy } \\
\hline No chemotherapy & 32 & 13.8 \\
\hline Platinum based & 100 & 43.1 \\
\hline Platinum/taxane based & 72 & 31.0 \\
\hline Other regimen & 25 & 10.8 \\
\hline Missing & 3 & 1.3 \\
\hline
\end{tabular}

$\mathrm{FIGO}=$ International Federation of Gynaecology and Obstetrics; NOS = not otherwise specified patients with stage III/IV disease. Optimal debulking was achieved in $61(96.8 \%)$ stage I/II patients and $48(31.0 \%)$ stage III/IV patients. First-line chemotherapy regimens were platinum based in $100(43.1 \%)$ patients and platinum- and taxane-based in 72 (31.0\%) patients. Total $25(10.8 \%)$ patients were treated with other regimens, and $32(13.8 \%)$ patients did not receive chemotherapy because of stage Ia disease, comorbidity or treatment refusal.

For stage I/II patient, 5-year PFS was $73.0 \%$ (median 53 months, range $0-207$ ) and 5 -year OS was $78.9 \%$ (median 58 months, range $0-207$ ). For stage III/IV patients, 5-year PFS was $13.8 \%$ (median 13.8 months, range $0-149$ ) and 5 -year OS was $22.3 \%$ (median 21 months, range $0-213$ ). Five-year survival for the whole cohort was $39.2 \%$.

\section{Immunostaining and RT - PCR}

The number of non-evaluable primary tumours due to core loss during staining procedures or absence of tumour tissue ranged from $2(0.9 \%)$ for HER-2/neu staining to $10(4.3 \%)$ for $\mathrm{pERK}$ staining. Positive staining was present in $6.2 \%$ of tumours for EGFR, $5.1 \%$ of tumours for HER-2/neu, $11.8 \%$ tumours for pEGFR, $100 \%$ of tumours for total AKT, $8.3 \%$ of tumours for pAKT and $36.9 \%$ of tumours for pERK (Table 2; Figure 1). Of 224 tumours, 69 $(30.8 \%)$ showed completely negative PTEN staining. None of the tumour samples stained positive for EGFRvIII, nor could EGFRvIII be detected by RT - PCR. Staining for pERK was more frequent in tumour samples obtained after three or six cycles of chemotherapy compared to paired primary tumour samples (65 vs 37\%, $P=0.020$ ). For all other proteins, staining patterns in primary tumours were comparable to paired residual or recurrent tumour samples (Table 2).

Unexpectedly, PTEN staining was positively correlated with pAKT staining $(P=0.034)$. No associations were found between other proteins (data not shown).

\section{Clinicopathological characteristics}

Overexpression of EGFR was more frequent in non-serous tumours $(P=0.017$; Table 3$)$. Stage III/IV tumours more often showed overexpression of pAKT $(P=0.029)$. Loss of PTEN was related to stage I/II disease $(P=0.006)$. Furthermore, negative PTEN immunostaining was associated with non-serous tumour type ( $P=0.042$ ), occurring in $25 \%$ of serous, $39 \%$ of endometrioid, $42 \%$ of mucinous and $56 \%$ of clear cell tumours. No other associations between protein expression and clinicopathological variables were found.

\section{Response to chemotherapy and survival}

Univariate Cox regression analysis revealed that patients with a PTEN-negative tumour had a better PFS and OS (Table 4; $P<0.001$ and $P=0.037$, respectively). On the basis of recent publications dividing ovarian carcinomas into subgroups with specific molecular alterations (Bell, 2005; Press et al, 2008), we performed subgroup analyses for early and late stage patients, and for patients with grade III and undifferentiated carcinomas. Subgroup analysis for stage I/II and stage III/IV patients showed that PTEN predicts PFS only in the early stage group (HR $0.29,95 \%$ CI $0.095-0.9$, $P=0.032$ for stage I/II patients, HR 0.74 , 95\% CI $0.48-1.15$, $P=0.18$ for stage III/IV patients). Loss of PTEN also predicted improved PFS in 91 poorly differentiated serous carcinomas, of which 20 (22.0\%) were PTEN negative (HR 0.43, 95\% CI 0.23-0.83, $P=0.011)$.

In multivariate analysis PTEN staining $(P=0.015)$, FIGO stage $(P=0.013)$ and residual tumour after primary surgery $(P<0.001)$ independently predicted PFS (Table 5$)$. Tumour stage $(P=0.023)$ and residual tumour $(P<0.001)$, but not PTEN staining $(P=0.833)$ were significant prognostic factors in multivariate analysis for OS. 
Table 2 Results of immunostaining

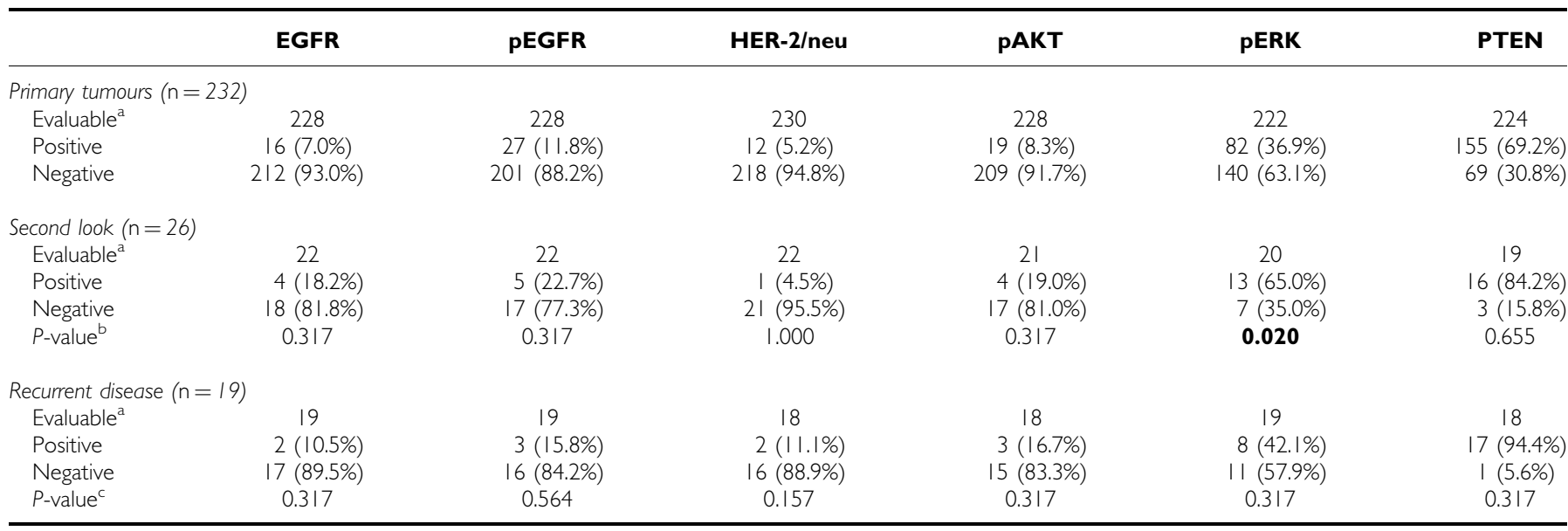

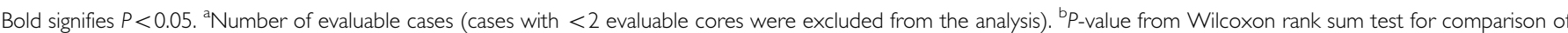
protein expression between tumour samples from primary surgery and from second look. ${ }^{C} P$-value from Wilcoxon rank sum test for comparison of protein expression between tumour samples from primary surgery and surgery for recurrent disease.

Other markers were not associated with survival. Protein expression did not predict response to platinum-based chemotherapy.

\section{DISCUSSION}

Our study in a large, well-defined series of epithelial ovarian cancer patients shows that PTEN-negative tumours might represent a subgroup of ovarian carcinomas with a relatively favourable prognosis. To our knowledge this is the first study describing a relationship between negative PTEN staining and improved survival in ovarian cancer. Although a relationship between negative PTEN staining and improved survival has been described for endometrial cancer patients (Risinger et al, 1998), previous studies in ovarian cancer found no or an inverse relationship between PTEN and prognosis (Schondorf et al, 2003; Wang et al, 2005; Lee et al, 2005a). These contrasting results could be explained by the fact that previous studies either did not have the power to evaluate possible relations with survival, or restricted their analysis to stage III/IV ovarian cancer patients. In the current study PTEN staining was of prognostic significance mainly in the stage I/II group and in poorly differentiated serous carcinomas.

We found negative PTEN expression in $30.8 \%$ of tumours, which is in agreement with previous studies (Wang et al, 2005; Lee et al, 2005a; Hashiguchi et al, 2006). In ovarian cancer, loss-ofheterozygosity $(\mathrm{LOH})$ at the PTEN locus (10q23.3) occurs in $31-$ $45 \%$ of tumours, whereas mutations of the second PTEN allele are relatively rare (Maxwell et al, 1998; Obata et al, 1998; Kurose et al, 2001). Loss of protein expression is therefore also thought to arise through other mechanisms, such as DNA methylation (Sansal and Sellers, 2004).

Interestingly, we showed a high rate of negative PTEN staining in endometrioid and clear cell tumours. A high rate of PTEN loss in clear cell and endometrioid carcinomas has also been shown in previous, much smaller studies (Obata et al, 1998; Hashiguchi et al, 2006). Both cancers are thought to at least partly arise from endometriosis. Sato et al (2000) showed that in three out of five ovarian carcinomas associated with endometriosis, $\mathrm{LOH}$ at $10 \mathrm{q} 23.3$ occurs in both the carcinoma and in endometriotic lesions, implicating that $\mathrm{LOH}$ is an early event in carcinogenesis and that PTEN is involved in the progression from endometriotic precursor lesion to clear cell or endometrioid ovarian cancer.

Our results show that negative PTEN staining is strongly associated with early stage disease and a non-serous tumour type. Recent studies suggest that ovarian carcinomas could be divided in two categories. The first category, called type I, includes low-grade serous, mucinous, clear cell and endometrioid tumour with frequent alterations in BRAF, KRAS and PTEN. Type I tumours are thought to arise from precursor lesions such as endometriosis and have a relatively good prognosis. In contrast, type II tumours, including high-grade serous and undifferentiated carcinomas characterised by p53 mutations and overexpression/amplification of HER-2/neu and AKT2, tend to show a highly aggressive behaviour (Shih and Kurman, 2004; Bell, 2005). In the present study, we identified a relationship of pAKT expression with late stage disease. Moreover, our previous work showed that overexpression of p53 mostly occurs in high-grade, late stage, serous carcinomas (de Graeff et al, 2006). Our combined results therefore support this model of ovarian carcinogenesis.

A recent study by Press et al (2008) suggests that type II ovarian tumours can be subclassified into three groups based on their BRCA1 status. Their results indicate that poorly differentiated serous carcinomas with BRCA1 mutations frequently show loss of PTEN. The molecular mechanism underlying the relationship between loss of PTEN and BRCA1 mutations in ovarian cancer remains unknown. Possibly, ineffective DNA repair in BRCA1linked tumours results in specific mutations of the PTEN gene (Foulkes, 2008; Saal et al, 2008). On the basis of these observations we performed survival analysis in a subgroup of 91 poorly differentiated serous carcinomas. We were able to show that loss of PTEN was indeed associated with improved PFS in this subgroup of ovarian carcinomas. Patients with BRCA1-linked hereditary tumours have a favourable survival compared to sporadic tumours, possibly because of a good response to chemotherapy (Boyd et al, 2000; Chetrit et al, 2008). The link between PTEN and BRCA1 status might therefore explain an improved disease outcome in a subgroup of patients with an otherwise very poor prognosis. In that case, IHC staining of PTEN may be a rapid way of identifying tumours most likely to carry BRCA1 mutations. Subsequently, those patients might benefit from treatments with agents selectively targeting BRCA mutant tumour cells, such as poly(ADP-ribose) polymerase 1 inhibitors (Farmer et al, 2005).

In the current study, loss of PTEN was associated with improved PFS, but not OS. As PFS is closely related to response to chemotherapy, these results might indicate that patients with PTEN negative tumours respond favourably to first-line therapy. In the current study we did not observe a relationship between PTEN status and response to chemotherapy. However, this analysis was limited to patients who had measurable disease before start of chemotherapy or measurable disease progression during 

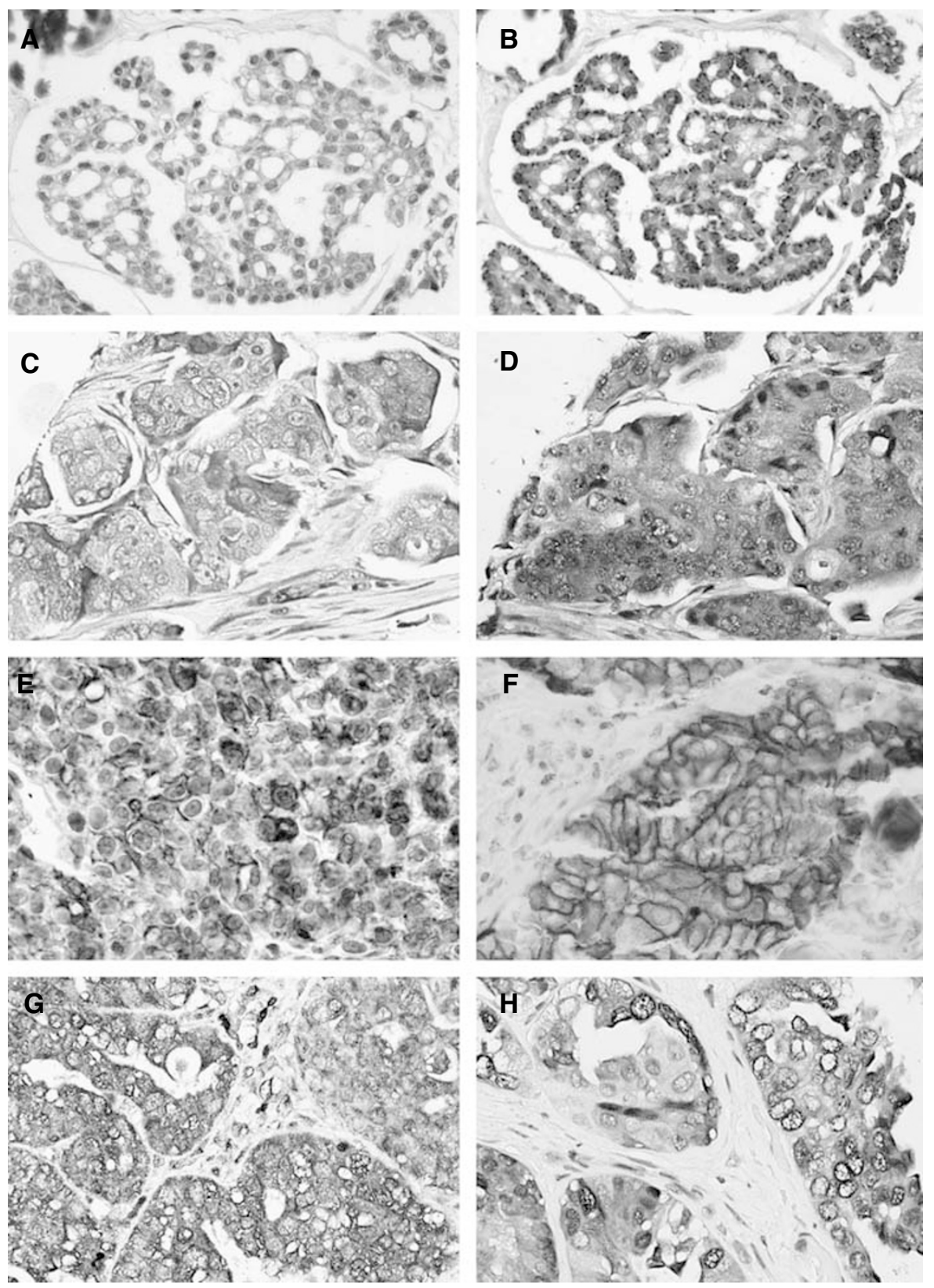

Figure I Results of immunostaining. (A) and (B) show positive immunostaining for epidermal growth factor receptor (EGFR) and pEGFR, respectively, in the same tumours. Positive immunostaining for PAKT and phosphatase and tensin homologue deleted on chromosome I0 (PTEN) in the same tumour is shown in $(\mathbf{C})$ and $(\mathbf{D})$, respectively. Figures $(\mathbf{E}-\mathbf{G})$ show positive immunostaining for EGFRvill (positive control, E), HER-2/neu $(\mathbf{F})$, pERK $(\mathbf{G})$ and total $\operatorname{AKT}(\mathbf{H})$.

treatment. Response to chemotherapy could therefore only be analysed in a subset of advanced-stage patients with a very poor prognosis. One possible explanation for the lack of association between negative PTEN staining and OS might be explained by the fact that tumours can acquire secondary mutations during or after platinum-based chemotherapy (Sakai et al, 2008). Once a patient presents with progressive or recurrent disease, these mutations may render the tumour insensitive to platinum-based chemotherapy irrespective of the PTEN status.

We did not observe any association between EGFR and HER-2/ neu immunostaining and disease outcome, confirming results of a previous study also from our institution (Van Der Zee et al, 1995). Previous studies on the relationship between EGFR or HER-2/neu overexpression and clinicopathological characteristics, response to chemotherapy and survival have shown conflicting results (Camilleri-Broet et al, 2004; Elie et al, 2004; Nielsen et al, 2004; Psyrri et al, 2005). One of the most important reasons for these inconclusive data is the considerable methodological variability among studies (Hall et al, 2004). Techniques used to determine marker expression, antibodies and scoring systems used for immunostaining vary widely between studies. For the present investigation, we aimed to use well-characterised antibodies that have been extensively studied in other tumour types, and, if possible, used well-defined scoring criteria that have been shown to be reproducible. We have sought to adhere to the REMARK guidelines for publishing prognostic factor studies (McShane et al, 2005). The use of these guidelines and of standardised methods should aid in increasing transparency and reproducibility of 
Table 3 Relationship between proteins and clinicopathological characteristics

\begin{tabular}{|c|c|c|c|c|c|c|c|c|c|c|c|c|c|c|c|c|c|c|}
\hline \multirow[b]{2}{*}{ Variable } & \multicolumn{3}{|c|}{ HER2 } & \multicolumn{3}{|c|}{ EGFR } & \multicolumn{3}{|c|}{ pEGFR } & \multicolumn{3}{|c|}{ PAKT } & \multicolumn{3}{|c|}{ pERK } & \multicolumn{3}{|c|}{ PTEN } \\
\hline & Neg & Pos & $P$ & Neg & Pos & $P$ & Neg & Pos & $P$ & Neg & Pos & $P$ & Neg & Pos & $P$ & Neg & Pos & $P$ \\
\hline \multicolumn{19}{|l|}{ Age } \\
\hline $\begin{array}{l}<58 \text { years } \\
>58 \text { years }\end{array}$ & $\begin{array}{l}110 / 113 \\
108 / 117\end{array}$ & $\begin{array}{l}3 / 113 \\
9 / 117\end{array}$ & 0.14 & $\begin{array}{l}106 / 112 \\
106 / 116\end{array}$ & $\begin{array}{l}6 / 112 \\
10 / 116\end{array}$ & 0.44 & $\begin{array}{l}99 / 113 \\
102 / 115\end{array}$ & $\begin{array}{l}14 / 113 \\
13 / 115\end{array}$ & 0.84 & $\begin{array}{l}104 / 114 \\
105 / 1 \mid 4\end{array}$ & $\begin{array}{l}10 / 114 \\
9 / 114\end{array}$ & 1.00 & $\begin{array}{l}69 / 108 \\
71 / 114\end{array}$ & $\begin{array}{l}39 / 108 \\
43 / 114\end{array}$ & 0.89 & $\begin{array}{l}38 / 111 \\
31 / 113\end{array}$ & $\begin{array}{l}73 / 111 \\
82 / 113\end{array}$ & 0.31 \\
\hline \multicolumn{19}{|c|}{ 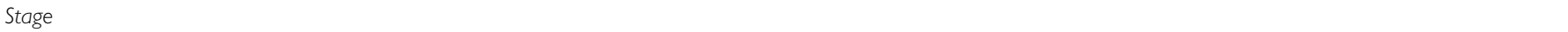 } \\
\hline \multicolumn{19}{|l|}{ Histology } \\
\hline $\begin{array}{l}\text { Serous } \\
\text { Other }\end{array}$ & $\begin{array}{l}123 / 128 \\
95 / 102\end{array}$ & $\begin{array}{l}5 / 128 \\
7 / 102\end{array}$ & 0.38 & $\begin{array}{l}123 / 127 \\
89 / 101\end{array}$ & $\begin{array}{l}4 / 127 \\
12 / 10 \mid\end{array}$ & 0.017 & $\begin{array}{l}111 / 127 \\
90 / 101\end{array}$ & $\begin{array}{l}16 / 127 \\
11 / 101\end{array}$ & 0.84 & $\begin{array}{c}115 / / 126 \\
94 / 102\end{array}$ & $\begin{array}{l}11 / 126 \\
8 / 102\end{array}$ & 1.00 & $\begin{array}{c}77 / 123 \\
63 / 99\end{array}$ & $\begin{array}{c}46 / 123 \\
36 / 99\end{array}$ & 0.89 & $\begin{array}{l}31 / 124 \\
38 / 100\end{array}$ & $\begin{array}{l}93 / 124 \\
62 / 100\end{array}$ & 0.042 \\
\hline \multicolumn{19}{|l|}{ Grade } \\
\hline $\begin{array}{l}\text { |/II } \\
\text { III/undiff }\end{array}$ & $\begin{array}{c}84 / 89 \\
112 / 118\end{array}$ & $\begin{array}{l}5 / 89 \\
6 / 118\end{array}$ & 1.00* & $\begin{array}{c}82 / 87 \\
109 / 118\end{array}$ & $\begin{array}{l}5 / 87 \\
9 / 118\end{array}$ & 0.78 & $\begin{array}{c}75 / 88 \\
107 / 117\end{array}$ & $\begin{array}{l}13 / 88 \\
10 / 117\end{array}$ & 0.18 & $\begin{array}{c}85 / 89 \\
104 / 116\end{array}$ & $\begin{array}{c}4 / 89 \\
12 / 116\end{array}$ & 0.19 & $\begin{array}{c}49 / 85 \\
76 / 114\end{array}$ & $\begin{array}{c}36 / 85 \\
38 / 114\end{array}$ & 0.24 & $\begin{array}{l}32 / 87 \\
31 / 114\end{array}$ & $\begin{array}{c}55 / 87 \\
83 / 114\end{array}$ & 0.17 \\
\hline
\end{tabular}

Neg = negative; Pos = positive; Res. tumour = residual tumour after primary surgery; undiff = undifferentiated. $P$-values are derived from the $\chi^{2}$-test or Fischer's exact test, where appropriate (*signifies the use of the Fischer's exact test).

Table 4 Results of univariate survival analysis

\begin{tabular}{llcc}
\hline & \multicolumn{2}{c}{ Univariate Cox regression analysis } \\
\cline { 2 - 4 } & $\begin{array}{l}\text { Hazard } \\
\text { ratio }\end{array}$ & $\begin{array}{c}\mathbf{9 5 \%} \text { confidence } \\
\text { interval }\end{array}$ & P-value \\
\hline Progression-free survival & & & \\
EGFR positive & 0.55 & $0.26-1.17$ & 0.12 \\
HER-2/neu positive & 0.98 & $0.46-2.10$ & 0.96 \\
PEGFR positive & 0.62 & $0.35-1.06$ & 0.09 \\
PAKT positive & 0.88 & $0.46-1.67$ & 0.69 \\
PERK positive & 1.09 & $0.77-1.54$ & 0.64 \\
PTEN negative & $\mathbf{0 . 4 8}$ & $\mathbf{0 . 3 2}-\mathbf{0 . 7 2}$ & $<\mathbf{0 . 0 0 1}$ \\
& & & \\
Overall survival & & $0.43-1.65$ & 0.43 \\
EGFR positive & 0.84 & $0.48-2.20$ & 0.94 \\
HER-2/neu positive & 1.02 & $0.36-1.39$ & 0.13 \\
PEGFR positive & 0.64 & $0.58-1.91$ & 0.86 \\
PAKT positive & 1.05 & $0.73-1.48$ & 0.84 \\
PERK positive & 1.04 & $\mathbf{0 . 4 4}-\mathbf{0 . 0 9 7}$ & $\mathbf{0 . 0 3 7}$ \\
PTEN negative & $\mathbf{0 . 6 6}$ & & \\
\hline
\end{tabular}

Bold signifies $P<0.05$.

prognostic factor studies in ovarian cancer and other tumour types.

As tumours showing evidence of strong signalling through a particular pathway are thought to have a high chance of responding to therapies directed against this pathway, the identification of reliable biomarkers could aid in selecting patients who are most likely to benefit from targeted therapy (Bild et al, 2006). Results of different clinical trials show that positive immunostaining for HER-2/neu or EGFR does not reliably predict response to ErbB-targeted therapy (Ciardiello and Tortora, 2008). A possible better marker of response to EGFR- and HER-2/neutargeted therapies is activation or downregulation of downstream pathways. Indeed, positive immunostaining for pAKT, pERK, PTEN and EGFRvIII has been reported to predict sensitivity to EGFR tyrosine kinase inhibitors in non-small-cell lung cancer and glioblastoma (Han et al, 2004; Mellinghoff et al, 2005). The association of pAKT and $\mathrm{pERK}$ in relation to response to
Table 5 Results of multivariate survival analysis

\begin{tabular}{|c|c|c|c|}
\hline & \multicolumn{3}{|c|}{ Multivariate Cox regression analysis } \\
\hline & $\begin{array}{c}\text { Hazard } \\
\text { ratio }\end{array}$ & $\begin{array}{l}95 \% \text { confidence } \\
\text { interval }\end{array}$ & $P$-value \\
\hline \multicolumn{4}{|l|}{ Progression-free survival } \\
\hline PTEN-negative tumour & 0.57 & $0.36-0.90$ & 0.015 \\
\hline Age $>58$ years & 1.09 & $0.74-1.60$ & 0.671 \\
\hline FIGO stage III/IV & $2.5 I$ & $1.21-5.19$ & 0.013 \\
\hline Serous tumour type & 1.44 & $0.92-2.24$ & 0.109 \\
\hline Differentiation grade III/IV & 1.40 & $0.89-2.19$ & 0.144 \\
\hline Suboptimal debulking & 2.37 & $1.43-3.50$ & $<0.001$ \\
\hline \multicolumn{4}{|l|}{ Overall survival } \\
\hline PTEN-negative tumour & 0.96 & $0.62-1.47$ & 0.833 \\
\hline Age $>58$ years & 1.24 & $0.83-1.83$ & 0.291 \\
\hline FIGO stage III/IV & 2.56 & $1.14-5.74$ & 0.023 \\
\hline Serous tumour type & 1.46 & $0.93-2.76$ & 0.100 \\
\hline Differentiation grade III/IV & 1.50 & $0.94-2.38$ & 0.090 \\
\hline Suboptimal debulking & 2.51 & $1.57-4.00$ & $<0.001$ \\
\hline
\end{tabular}

PTEN = phosphatase and tensin homologue deleted on chromosome 10 $\mathrm{FIGO}=$ International Federation of Gynaecology and Obstetrics. Bold signifies $P<0.05$

ErbB-targeted therapy in ovarian cancer has not been studied yet, but expression of these proteins might be used as a marker of responsiveness to targeted therapies. Our results show that 8.3 and $36.9 \%$ of tumours show positive pAKT and pERK staining, respectively, indicating that only a subgroup of patients might benefit from agents directed against these pathways. As pERK is overexpressed in approximately one-third of primary ovarian tumours and $65 \%$ of tumour samples from primary chemoresistant tumours obtained after chemotherapy, treatment of patients with Ras/Raf/MEK/Erk-targeted agents appears to be an interesting therapeutic option (Messersmith et al, 2006).

In contrast to previous studies, we show a low percentage of pAKT-positive tumours (Altomare et al, 2004; Wang et al, 2005). The discrepancy between our results and those obtained in previous studies is not likely to be due to methodological variability. We have used the same well-characterised antibody 
that was used in previous studies, with a comparable staining protocol. In all our experiments, the ovarian cancer cell line A2780 served as a positive control. Expression of pAKT in this cell line was confirmed by western blotting (data not shown). In agreement with previous large studies, we also show a relatively low percentage of EGFR- and HER-2/neu-overexpressing tumours (Bookman et al, 2003; Lassus et al, 2006). We therefore conclude that in this group of ovarian carcinomas, signalling of EGFRs via the AKT pathway might be important only in specific subgroups of ovarian tumours.

Surprisingly, we identified a significant relationship between positive expression of AKT and positive expression of PTEN. The role of PTEN as a negative regulator of AKT is well documented in both cell line models and tumour samples (Stambolic et al, 1998; Sun et al, 1999; Kurose et al, 2001; Choe et al, 2003). However, others have also identified a positive correlation between expressions of the two proteins by immunostaining (Panigrahi et al, 2004; Slipicevic et al, 2005; Wang et al, 2005). This might mean that in tumours, the regulatory relationship between AKT and PTEN is not linear. In breast and ovarian cancer, it has been shown that aberrations of the PI3K and PTEN genes are mutually exclusive (Saal et al, 2005; Press et al, 2008), resulting in constitutive activation of the PI3K pathway in the presence of an intact PTEN. Loss of PTEN may also contribute to tumourigenesis and progression via AKT-independent pathways, such as the p53 pathway (Blanco-Aparicio et al, 2007).

In contrast to available data in literature we did not detect any EGFRvIII in this large group of ovarian carcinomas. Moscatello et al reported that EGFRvIII is expressed in $75 \%$ of ovarian tumours, but this high percentage could not be confirmed in subsequent studies (Jungbluth et al, 2003; Lassus et al, 2006). We determined EGFRvIII status by immunohistochemistry using the well-defined antibody DH8.3 and verified our results at the RNA level by RT-PCR on a subset of 45 tumours showing positive immunostaining for EGFR or downstream targets. As EGFRvIII heterodimerises with wtEGFR, is constitutively phosphorylated and activates AKT and to a lesser extent ERK, we hypothesised that the chance of finding EGFRvIII-positive tumours was largest in this subgroup (Montgomery et al, 1995; Li et al, 2004; Luwor et al, 2004). As we did not detect any EGFRvIII positivity in this subgroup, nor in 10 tumours that did not overexpress any of the studied markers, our data strongly suggest that EGFRvIII signalling does not play a major role in ovarian cancer.

In the current retrospective study we investigated protein expression in a large well-defined patient population. However, our results showed that protein expression was mainly important in specific patient groups. Unfortunately, these subgroups were too small to perform valid multivariate analysis. Furthermore, not all patients received the same chemotherapeutic treatment. Future studies should determine the prognostic value of PTEN staining, especially in early stage patients and poorly differentiated serous tumours, in large prospective studies including homogeneously treated patients.

In summary, we demonstrated that negative PTEN staining is associated with favourable patient and tumour characteristics, and independently predicts improved PFS. The importance of pAKT and PERK expression as downstream markers of responsiveness to receptor tyrosine kinase-targeted therapies deserves to be evaluated in clinical trials. A better understanding of these pathways and their role in ovarian cancer will enable us to use targeted drugs more efficiently, and to identify (groups of) genes that predict prognosis more accurately.

Supplementary Information accompanies the paper on British Journal of Cancer website (http://www.nature.com/bjc)

\section{REFERENCES}

Altomare DA, Wang HQ, Skele KL, De Rienzo A, Klein-Szanto AJ, Godwin AK, Testa JR (2004) AKT and mTOR phosphorylation is frequently detected in ovarian cancer and can be targeted to disrupt ovarian tumor cell growth. Oncogene 23: 5853-5857

Bell DA (2005) Origins and molecular pathology of ovarian cancer. Mod Pathol 18(Suppl 2): S19-S32

Bhoola S, Hoskins WJ (2006) Diagnosis and management of epithelial ovarian cancer. Obstet Gynecol 107: 1399-1410

Bild AH, Potti A, Nevins JR (2006) Linking oncogenic pathways with therapeutic opportunities. Nat Rev Cancer 6: 735-741

Blanco-Aparicio C, Renner O, Leal JF, Carnero A (2007) PTEN, more than the AKT pathway. Carcinogenesis 28: 1379-1386

Bookman MA, Darcy KM, Clarke-Pearson D, Boothby RA, Horowitz IR (2003) Evaluation of monoclonal humanized anti-HER2 antibody, trastuzumab, in patients with recurrent or refractory ovarian or primary peritoneal carcinoma with overexpression of HER2: a phase II trial of the Gynecologic Oncology Group. J Clin Oncol 21: 283-290

Boyd J, Sonoda Y, Federici MG, Bogomolniy F, Rhei E, Maresco DL, Saigo PE, Almadrones LA, Barakat RR, Brown CL, Chi DS, Curtin JP, Poynor EA, Hoskins WJ (2000) Clinicopathologic features of BRCA-linked and sporadic ovarian cancer. JAMA 283: 2260-2265

Bremer E, Samplonius DF, van Genne L, Dijkstra MH, Kroesen BJ, de Leij LF, Helfrich W (2005) Simultaneous inhibition of epidermal growth factor receptor (EGFR) signaling and enhanced activation of tumor necrosis factor-related apoptosis-inducing ligand (TRAIL) receptor-mediated apoptosis induction by an scFv:sTRAIL fusion protein with specificity for human EGFR. $J$ Biol Chem 280: $10025-10033$

Camilleri-Broet S, Hardy-Bessard AC, Le Tourneau A, Paraiso D, Levrel O, Leduc B, Bain S, Orfeuvre H, Audouin J, Pujade-Lauraine E (2004) HER-2 overexpression is an independent marker of poor prognosis of advanced primary ovarian carcinoma: a multicenter study of the GINECO group. Ann Oncol 15: 104-112
Cancer Committee of the International Federation of Gynaecology and Obstetrics (1986) Staging announcement: FIGO Cancer Committee. Gynecol Oncol 25: 383-385

Chetrit A, Hirsh-Yechezkel G, Ben-David Y, Lubin F, Friedman E, Sadetzki S (2008) Effect of BRCA1/2 mutations on long-term survival of patients with invasive ovarian cancer: the national Israeli study of ovarian cancer. J Clin Oncol 26: 20-25

Choe G, Horvath S, Cloughesy TF, Crosby K, Seligson D, Palotie A, Inge L, Smith BL, Sawyers CL, Mischel PS (2003) Analysis of the phosphatidylinositol $3^{\prime}$-kinase signaling pathway in glioblastoma patients in vivo. Cancer Res 63: 2742-2746

Ciardiello F, Caputo R, Bianco R, Damiano V, Pomatico G, De Placido S, Bianco AR, Tortora G (2000) Antitumor effect and potentiation of cytotoxic drugs activity in human cancer cells by ZD-1839 (Iressa), an epidermal growth factor receptor-selective tyrosine kinase inhibitor. Clin Cancer Res 6: 2053-2063

Ciardiello F, Tortora G (2008) EGFR antagonists in cancer treatment. $N$ Engl J Med 358: $1160-1174$

Crijns AP, Duiker EW, De Jong S, Willemse PH, Van Der Zee AG, De Vries EG (2006a) Molecular prognostic markers in ovarian cancer: toward patient-tailored therapy. Int J Gynecol Cancer 16(Suppl 1): 152-165

Crijns AP, Gerbens F, Plantinga AE, Meersma GJ, De Jong S, Hofstra RM, De Vries EG, Van Der Zee AG, de Bock GH, te Meerman GJ (2006b) A biological question and a balanced (orthogonal) design: the ingredients to efficiently analyze two-color microarrays with confirmatory factor analysis. BMC Genomics 7: 232

Crijns APG, Boezen HM, Schouten JP, Arts HJG, Hofstra RMW, Willemse PHB, Vries de EGE, Van Der Zee AG (2003) Prognostic factors in ovarian cancer: current evidence and future prospects. Eur J Cancer S 1: $127-145$ Cunningham MP, Essapen S, Thomas H, Green M, Lovell DP, Topham C, Marks C, Modjtahedi H (2005) Coexpression, prognostic significance and predictive value of EGFR, EGFRvIII and phosphorylated EGFR in colorectal cancer. Int J Oncol 27: $317-325$ 
de Graeff P, Hall J, Crijns AP, de Bock GH, Paul J, Oien KA, ten Hoor KA, de Jong S, Hollema H, Bartlett JM, Brown R, van der Zee AG (2006) Factors influencing p53 expression in ovarian cancer as a biomarker of clinical outcome in multicentre studies. Br J Cancer 95: 627-633

Elie C, Geay JF, Morcos M, Le Tourneau A, Girre V, Broet P, Marmey B, Chauvenet L, Audouin J, Pujade-Lauraine E, Camilleri-Broet S (2004) Lack of relationship between EGFR-1 immunohistochemical expression and prognosis in a multicentre clinical trial of 93 patients with advanced primary ovarian epithelial cancer (GINECO group). $\mathrm{Br} J$ Cancer 91: $470-475$

Farmer H, McCabe N, Lord CJ, Tutt AN, Johnson DA, Richardson TB, Santarosa M, Dillon KJ, Hickson I, Knights C, Martin NM, Jackson SP, Smith GC, Ashworth A (2005) Targeting the DNA repair defect in BRCA mutant cells as a therapeutic strategy. Nature 434: 917-921

Foulkes WD (2008) BRCA1-sowing the seeds crooked in the furrow. Nat Genet 40: 8-9

Gimm O, Perren A, Weng LP, Marsh DJ, Yeh JJ, Ziebold U, Gil E, Hinze R, Delbridge L, Lees JA, Mutter GL, Robinson BG, Komminoth P, Dralle H, Eng C (2000) Differential nuclear and cytoplasmic expression of PTEN in normal thyroid tissue, and benign and malignant epithelial thyroid tumors. Am J Pathol 156: $1693-1700$

Hall J, Paul J, Brown R (2004) Critical evaluation of p53 as a prognostic marker in ovarian cancer. Expert Rev Mol Med 2004: 1-20

Han SW, Hwang PG, Chung DH, Kim DW, Im SA, Kim YT, Kim TY, Heo DS, Bang YJ, Kim NK (2004) Epidermal growth factor receptor (EGFR) downstream molecules as response predictive markers for gefitinib (Iressa (R), ZD1839) in chemotherapy-resistant non-small cell lung cancer. Int $J$ Cancer 113: 109-115

Hashiguchi Y, Tsuda H, Inoue T, Berkowitz RS, Mok SC (2006) PTEN expression in clear cell adenocarcinoma of the ovary. Gynecol Oncol 101: $71-75$

Ji H, Zhao X, Yuza Y, Shimamura T, Li D, Protopopov A, Jung BL McNamara K, Xia H, Glatt KA, Thomas RK, Sasaki H, Horner JW, Eck M, Mitchell A, Sun Y, Al Hashem R, Bronson RT, Rabindran SK, Discafan CM, Maher E, Shapiro GI, Meyerson M, Wong KK (2006) Epidermal growth factor receptor variant III mutations in lung tumorigenesis and sensitivity to tyrosine kinase inhibitors. Proc Natl Acad Sci USA 103: $7817-7822$

Jungbluth AA, Stockert E, Huang HJ, Collins VP, Coplan K, Iversen K, Kolb D, Johns TJ, Scott AM, Gullick WJ, Ritter G, Cohen L, Scanlan MJ, Cavenee WK, Old LJ (2003) A monoclonal antibody recognizing human cancers with amplification/overexpression of the human epidermal growth factor receptor. Proc Natl Acad Sci USA 100: 639-644

Kurose K, Zhou XP, Araki T, Cannistra SA, Maher ER, Eng C (2001) Frequent loss of PTEN expression is linked to elevated phosphorylated Akt levels, but not associated with p27 and cyclin D1 expression, in primary epithelial ovarian carcinomas. Am J Pathol 158: 2097-2106

Lassus H, Sihto H, Leminen A, Joensuu H, Isola J, Nupponen NN, Butzow R (2006) Gene amplification, mutation, and protein expression of EGFR and mutations of ERBB2 in serous ovarian carcinoma. J Mol Med 84: $671-681$

Lebeau A, Deimling D, Kaltz C, Sendelhofert A, Iff A, Luthardt B, Untch M, Lohrs U (2001) Her-2/neu analysis in archival tissue samples of human breast cancer: comparison of immunohistochemistry and fluorescence in situ hybridization. J Clin Oncol 19: 354-363

Lee JS, Choi YD, Choi C, Lee MC, Park CS, Min KW (2005a) Expression of PTEN in ovarian epithelial tumors and its relation to tumor behavior and growth. Anal Quant Cytol Histol 27: 202-210

Lee S, Choi EJ, Jin C, Kim DH (2005b) Activation of PI3K/Akt pathway by PTEN reduction and PIK3CA mRNA amplification contributes to cisplatin resistance in an ovarian cancer cell line. Gynecol Oncol 97: $26-34$

Li B, Yuan M, Kim IA, Chang CM, Bernhard EJ, Shu HK (2004) Mutant epidermal growth factor receptor displays increased signaling through the phosphatidylinositol-3 kinase/AKT pathway and promotes radioresistance in cells of astrocytic origin. Oncogene 23: 4594-4602

Luwor RB, Zhu HJ, Walker F, Vitali AA, Perera RM, Burgess AW, Scott AM, Johns TG (2004) The tumor-specific de2-7 epidermal growth factor receptor (EGFR) promotes cells survival and heterodimerizes with the wild-type EGFR. Oncogene 23: 6095-6104

Maxwell GL, Risinger JI, Tong B, Shaw H, Barrett JC, Berchuck A, Futreal PA (1998) Mutation of the PTEN tumor suppressor gene is not a feature of ovarian cancers. Gynecol Oncol 70: 13-16
McShane LM, Altman DG, Sauerbrei W, Taube SE, Gion M, Clark GM (2005) REporting recommendations for tumour MARKer prognostic studies (REMARK). Br I Cancer 93: 387-391

Mellinghoff IK, Wang MY, Vivanco I, Haas-Kogan DA, Zhu S, Dia EQ, Lu KV, Yoshimoto K, Huang JH, Chute DJ, Riggs BL, Horvath S, Liau LM, Cavenee WK, Rao PN, Beroukhim R, Peck TC, Lee JC, Sellers WR, Stokoe D, Prados M, Cloughesy TF, Sawyers CL, Mischel PS (2005) Molecular determinants of the response of glioblastomas to EGFR kinase inhibitors. N Engl J Med 353: 2012-2024

Messersmith WA, Hidalgo M, Carducci M, Eckhardt SG (2006) Novel targets in solid tumors: MEK inhibitors. Clin Adv Hematol Oncol 4: $831-836$

Montgomery RB, Guzman J, O'Rourke DM, Stahl WL (2000) Expression of oncogenic epidermal growth factor receptor family kinases induces paclitaxel resistance and alters beta-tubulin isotype expression. $J$ Biol Chem 275: $17358-17363$

Montgomery RB, Moscatello DK, Wong AJ, Cooper JA, Stahl WL (1995) Differential modulation of mitogen-activated protein (MAP) kinase/ extracellular signal-related kinase kinase and MAP kinase activities by a mutant epidermal growth factor receptor. J Biol Chem 270: $30562-30566$

Moscatello DK, Holgado-Madruga M, Godwin AK, Ramirez G, Gunn G, Zoltick PW, Biegel JA, Hayes RL, Wong AJ (1995) Frequent expression of a mutant epidermal growth factor receptor in multiple human tumors. Cancer Res 55: 5536-5539

Nagane M, Levitzki A, Gazit A, Cavenee WK, Huang HJ (1998) Drug resistance of human glioblastoma cells conferred by a tumor-specific mutant epidermal growth factor receptor through modulation of Bcl-XI and caspase-3-like proteases. Proc Natl Acad Sci USA 95: 5724-5729

Nielsen JS, Jakobsen E, Holund B, Bertelsen K, Jakobsen A (2004) Prognostic significance of $\mathrm{p} 53$, Her-2, and EGFR overexpression in borderline and epithelial ovarian cancer. Int J Gynecol Cancer 14: $1086-1096$

Obata K, Morland SJ, Watson RH, Hitchcock A, Chenevix-Trench G, Thomas EJ, Campbell IG (1998) Frequent PTEN/MMAC mutations in endometrioid but not serous or mucinous epithelial ovarian tumors. Cancer Res 58: 2095-2097

Panigrahi AR, Pinder SE, Chan SY, Paish EC, Robertson JF, Ellis IO (2004) The role of PTEN and its signalling pathways, including AKT, in breast cancer; an assessment of relationships with other prognostic factors and with outcome. I Pathol 204: $93-100$

Pedersen MW, Meltorn M, Damstrup L, Poulsen HS (2001) The type III epidermal growth factor receptor mutation. Biological significance and potential target for anti-cancer therapy. Ann Oncol 12: 745-760

Press JZ, De LA, Boyd N, Young S, Troussard A, Ridge Y, Kaurah P, Kalloger SE, Blood KA, Smith M, Spellman PT, Wang Y, Miller DM, Horsman D, Faham M, Gilks CB, Gray J, Huntsman DG (2008) Ovarian carcinomas with genetic and epigenetic BRCA1 loss have distinct molecular abnormalities. BMC Cancer 8: 17

Psyrri A, Kassar M, Yu Z, Bamias A, Weinberger PM, Markakis S, Kowalski D, Camp RL, Rimm DL, Dimopoulos MA (2005) Effect of epidermal growth factor receptor expression level on survival in patients with epithelial ovarian cancer. Clin Cancer Res 11: 8637-8643

Qiu L, Di W, Jiang Q, Scheffler E, Derby S, Yang J, Kouttab N, Wanebo H, Yan B, Wan Y (2005) Targeted inhibition of transient activation of the EGFR-mediated cell survival pathway enhances paclitaxel-induced ovarian cancer cell death. Int J Oncol 27: 1441 - 1448

Risinger JI, Hayes K, Maxwell GL, Carney ME, Dodge RK, Barrett JC, Berchuck A (1998) PTEN mutation in endometrial cancers is associated with favorable clinical and pathologic characteristics. Clin Cancer Res 4: $3005-3010$

Saal LH, Gruvberger-Saal SK, Persson C, Lovgren K, Jumppanen M, Staaf J, Jonsson G, Pires MM, Maurer M, Holm K, Koujak S, Subramaniyam S, Vallon-Christersson J, Olsson H, Su T, Memeo L, Ludwig T, Ethier SP, Krogh M, Szabolcs M, Murty VV, Isola J, Hibshoosh H, Parsons R, Borg A (2008) Recurrent gross mutations of the PTEN tumor suppressor gene in breast cancers with deficient DSB repair. Nat Genet 40: $102-107$

Saal LH, Holm K, Maurer M, Memeo L, Su T, Wang X, Yu JS, Malmstrom PO, Mansukhani M, Enoksson J, Hibshoosh H, Borg A, Parsons R (2005) PIK3CA mutations correlate with hormone receptors, node metastasis, and ERBB2, and are mutually exclusive with PTEN loss in human breast carcinoma. Cancer Res 65: 2554-2559

Sakai W, Swisher EM, Karlan BY, Agarwal MK, Higgins J, Friedman C, Villegas E, Jacquemont C, Farrugia DJ, Couch FJ, Urban N, Taniguchi T 
(2008) Secondary mutations as a mechanism of cisplatin resistance in BRCA2-mutated cancers. Nature 451: 1116-1120

Sansal I, Sellers WR (2004) The biology and clinical relevance of the PTEN tumor suppressor pathway. J Clin Oncol 22: 2954-2963

Sato N, Tsunoda H, Nishida M, Morishita Y, Takimoto Y, Kubo T, Noguchi M (2000) Loss of heterozygosity on 10q23.3 and mutation of the tumor suppressor gene PTEN in benign endometrial cyst of the ovary: possible sequence progression from benign endometrial cyst to endometrioid carcinoma and clear cell carcinoma of the ovary. Cancer Res 60: $7052-7056$

Schondorf T, Gohring UJ, Roth G, Middel I, Becker M, Moser N, Valter MM, Hoopmann M (2003) Time to progression is dependent on the expression of the tumour suppressor PTEN in ovarian cancer patients. Eur J Clin Invest 33: 256-260

Scully RE (ed) (2004) Histological typing of ovarian tumours. In International Histological Classification of Tumours, World Health Organization, pp $11-19$. Springer: Berlin

Shih I, Kurman RJ (2004) Ovarian tumorigenesis: a proposed model based on morphological and molecular genetic analysis. Am J Pathol 164: $1511-1518$

Skirnisdottir I, Seidal T, Sorbe B (2004) A new prognostic model comprising p53, EGFR, and tumor grade in early stage epithelial ovarian carcinoma and avoiding the problem of inaccurate surgical staging. Int J Gynecol Cancer 14: 259-270
Slipicevic A, Holm R, Nguyen MT, Bohler PJ, Davidson B, Florenes VA (2005) Expression of activated Akt and PTEN in malignant melanomas: relationship with clinical outcome. Am J Clin Pathol 124: $528-536$

Stambolic V, Suzuki A, de la Pompa JL, Brothers GM, Mirtsos C, Sasaki T, Ruland J, Penninger JM, Siderovski DP, Mak TW (1998) Negative regulation of $\mathrm{PKB} / \mathrm{Akt}$-dependent cell survival by the tumor suppressor PTEN. Cell 95: 29-39

Sun H, Lesche R, Li DM, Liliental J, Zhang H, Gao J, Gavrilova N, Mueller B, Liu X, Wu H (1999) PTEN modulates cell cycle progression and cell survival by regulating phosphatidylinositol 3,4,5,-trisphosphate and Akt/ protein kinase B signaling pathway. Proc Natl Acad Sci USA 96: 6199-6204

Van Der Zee AG, Hollema H, Suurmeijer AJ, Krans M, Sluiter WJ, Willemse PH, Aalders JG, De Vries EG (1995) Value of P-glycoprotein, glutathione $S$-transferase pi, c-erbB-2, and p53 as prognostic factors in ovarian carcinomas. J Clin Oncol 13: 70-78

Wang Y, Kristensen GB, Helland A, Nesland JM, Borresen-Dale AL, Holm R (2005) Protein expression and prognostic value of genes in the erb-b signaling pathway in advanced ovarian carcinomas. Am J Clin Pathol 124: $392-401$

World Health Organization (1979) Handbook for Reporting Results of Cancer Treatment. WHO: Geneva

Yarden Y, Sliwkowski MX (2001) Untangling the ErbB signalling network. Nat Rev Mol Cell Biol 2: 127-137 